syndrome in his 16-year-old brother. The boy had excessive throat-clearing, hyperactivity, and choreiform movements. Antistreptolysin O and DNAse B titers were elevated and a throat culture was positive for GABHS. Serial MRI scans performed to assess basal ganglia morphology in relation to symptom severity before and during plasmapheresis showed an initial caudate measure greater than two standard deviations above the mean for healthy boys. Within 1 day of the first plasmapheresis, the caudate volume decreased $24 \%$, the putamen $12 \%$, and the globus pallidus $28 \%$. These fluctuations in the size of the basal ganglia correlated with the severity of symptoms of OCD which showed amelioration after plasmapheresis and a course of amoxicillin. The acute enlargement of the basal ganglia was most pronounced when the throat culture was positive for GAGHS. Less dramatic changes in size accompanied subsequent exacerbations of OCD, which occurred with negative throat cultures. (Giedd JN, Rapoport JL et al. Case study: Acute basal ganglia enlargement and obsessive-compulsive symptoms in an adolescent boy. LAm Acad Child Adolesc Psychiatry July 1996;35:913-915). (Reprints: Dr Giedd, NIMH, Child Psychiatry Branch, Building 10, Room 6N240, 10 Center Drive MSC 1600, Bethesda, MD 20892).

COMMENT. A link between obsessive-compulsive disorder and basal ganglia dysfunction is supported by this case-study. The swelling of the basal ganglia was thought to represent an inflammatory reaction with edema secondary to a cross-reaction of antibodies against the invading bacteria.

An association between B-hemolytic streptococcal infection and Tourette's syndrome in children with ADHD was previously correlated with serum antibodies against human caudate nucleus sections and elevated antistreptolysin titers in a study at Brown University, RI. (Kiessling LS et al. see Progress in Pediatric Neurology II, PNB Publ, 1994, pp236-7). Immunological treatments for autoimmune neuropsychiatric disorders associated with streptococcal infections, including ADHD and co-morbid symptoms, deserve further study.

\title{
EARLY SCREENING FOR LEARNING DISABILITIES
}

The value of child health surveillance (CHS) practices in early detection of mild to moderate learning difficulties (LD) was investigated at the North and West Belfast Community Paediatric Unit, Belfast, N Ireland. The prevalence of learning difficulties in this deprived inner city area was $16 \%$. Only $6 \%$ of children with LD were identified by the CHS in the preschool period. Perinatal variables associated with LD were lower social class, prematurity, male sex, and birth to an unmarried mother. Risk factors used in the CHS which proved to be insensitive included speech delay, poor parenting, behavior problems, enuresis, poor visual acuity, and otitis media with effusion. (Corrigan N, Stewart $M$ et al. Predictive value of preschool surveillance in detecting learning difficulties. Arch Dis Child 1996;74:517-521). (Respond: Dr N Corrigan, Altnagelvin Area Hospital, Londonderry, N Ireland).

COMMENT. Child Health Surveillance (CHS) by health visitors, at birth, 6 weeks, 6,12 , and 18 months, 2,3 , and 4 years, failed to detect the majority of children with mild learning difficulties and missed $38 \%$ of the moderately learning disabled. Retrospective analysis of the child health record failed to identify a model to predict children with later LD. The failure of CHS in this setting was attributed to a combination of poor test sensitivity and the overlap of LD with variants of developmental norms. Nursery school and preschool 
surveillance, and increased parental and professional awareness could provide more accurate early detection of LD children.

\section{BUSSELTON STUDY OF BEHAVIOR DISORDER PREVENTION}

The long-term follow-up in 1993 of 209 adults, aged 27 to 29 years, who as children were enrolled in the Busselton Population six-year controlled study of prevention of children's behavior disorders is reported from Claremont, Western Australia. Ninety percent of the original cohort responded to a questionnaire detailing their present social situation and habits, educational achievements, and emotional well-being. In the initial Busselton study, 1964-1973, a 20- to 30-minute interview between physician and mother about the preschool child had reduced the incidence of behavioral disturbances at age 6 years. As adults, the study subjects had fewer neurotic symptoms and less depressive symptoms than controls, and more had a university degree. Study women were less obese and smoked less than controls. Behavior patterns noted at 6 years of age after preschool interventional counselling were reflected in the improvements recorded as adults when compared to controls. (Cullen KJ, Cullen AM. Long-term follow-up of the Busselton six-year controlled trial of prevention of children's behavior disorders. I Pediatr July 1996;129:136-9). (Reprints: Dr AM Cullen, 37 Riley Rd, Claremont 6010, Western Australia).

COMMENT. The interviewing and counselling of mothers of preschool children benefits the children's behavior at 6 years of age, and leads to increased emotional well-being and higher academic achievement in adult life. Women were benefited more than men. The decrease in eating problems among study children at 6 years of age were relected in the lesser incidence of obesity, less anxiety and depressive symptoms, and reduced tendency to smoke in female study subjects. University degrees had been attained by $34 \%$ of experimental women compared to $24 \%$ of the male subjects and $15 \%$ of both male and female controls.

In my ADHD Clinic at Children's Memorial Hospital, Chicago, I am continually impressed and concerned regarding the frequent negative approach of parents to the management of their hyperactive children. The adoption of a positive and gentle parental attitude toward modifying a child's behavior, as promoted in the Busselton study, should be encouraged early in a child's development. The obvious importance of services and expertise of child and family psychologists in County and City Mental Health Programs should be emphasized in Federal, State, and City government.

\section{STIMULANT THERAPY FOR BENIGN CHOREA AND ADHD}

A 6-year-old boy with benign familial chorea diagnosed at 1 year and ADHD evaluated and treated with methylphenidate (MPH) at 6 years is reported from the Department of Pediatrics, David Grant Medical Center, Travis Air Force Base, California. After MPH beginning with $2.5 \mathrm{mg}$ BD and gradually increasing to $7.5 \mathrm{mg} \mathrm{BD}$, his attention span, self-control, handwriting, and school performance were benefited as expected, but in addition, the chorea improved and his independent walking skills developed. On drug holidays, the chorea and gait problems regressed. (Friederich RL. Benign hereditary chorea improved on stimulant therapy. Pediatr Neurol May 1996;14:326-27). (Respond: Dr Friedrich, 60 MOS/SGOC, 101 Bodin Circle, Travis AFB, CA 94535).

COMMENT. The author suggests that chorea complicating ADHD should 